\title{
Precarização do trabalho profissional da/o assistente social na Amazônia brasileira: Particularidades do estado do Pará
}

\author{
Daniela Ribeiro Castilho ${ }^{1}$ \\ Maria Antônia Cardoso Nascimento ${ }^{2}$ \\ Vera Lúcia Batista Gomes ${ }^{3}$
}

\begin{abstract}
Resumo
Este artigo tem como objetivo problematizar o trabalho das/os assistentes sociais no atual estágio do capitalismo, as transformações societárias que impactam no mundo do trabalho e afetam as condições de trabalho dessas/es profissionais que atuam na política de Assistência Social, particularmente, no contexto amazônico. Com base em revisão da literatura, pesquisas documental e empírica realizadas no estado do Pará ${ }^{4}$, pode-se inferir que persiste um intenso processo de precarização do trabalho determinada pelas dimensões geográfica, cultural, étnico-racial e de classe social.

Palavras-chave

Trabalho; Serviço Social; Precarização; Amazônia.
\end{abstract}

Precariousness of the professional work of the social worker in the Brazilian Amazon: Particularities of the state of Pará

\section{Abstract}

This article aims to problematize the work of social workers in the current stage of capitalism, the societal transformations that impact the world of work and affect the working conditions of these professionals who work in the Social Assistance policy, particularly in the context Amazonian. Based on a literature review, documentary and empirical research carried out in the state of Pará, it can be inferred that an intense process of precarious work persists, determined by the geographical, cultural, ethnic-racial and social class dimensions.

Keywords

Work; Social Work; Precariousness; Amazon.

Artigo recebido em junho 2020

Artigo aprovado em agosto de 2020 


\section{Introdução}

A precarização do trabalho assalariado como uma das formas de garantia da reprodução ampliada do capital está presente em todas as profissões e, no caso do Serviço Social brasileiro, tem sido objeto de reflexão frequente no interior da categoria de assistentes sociais, principalmente com a retomada da gestão neoliberal do capitalismo nos últimos anos, que intensificou as formas de exploração da força de trabalho em geral e, em particular, de assistentes sociais que para Raichelis (2018) consiste na nova morfologia do trabalho no Serviço Social.

A abissal desigualdade que caracteriza a particularidade do desenvolvimento capitalista no Brasil não ocorre de forma homogênea colocando em evidência as disparidades regionais, principalmente quando se tratam das regiões Norte e Nordeste. A dimensão estrutural da desigualdade nacional instrumentaliza o trabalho e sua exploração bem como a proteção social, na Amazônia, a partir da sua inserção na divisão internacional do trabalho, como exportadora de matérias primas (commodities), bem como, pelas suas condições geográficas e socioculturais. Nesse sentido, apenas tem reconhecimento para o capital o que se transforma em mercadorias, ou seja, a biodiversidade vegetal e mineral.

Os territórios marcados pela existência de rios, lagos, ilhas, floresta, estradas, chuva e sol intenso, forte umidade, presença de insetos e animais etc., responsáveis muitas vezes, pelo distanciamento interpessoal e, por conseguinte, pelo deslocamento dos habitantes, em sua maioria de origem indígena, quilombola e ribeirinhos são vistos pelo Estado como obstáculos naturais ao que se defende como progresso e desenvolvimento, justificando a falta de infraestrutura adequada às condições geográfıcas singulares, bem como, o cumprimento constitucional dos meios e modos de vida das populações originárias, reconhecidas na Constituição Federal de 1988. A dimensão cultural quando positivada pelo Estado prioriza uma concepção multiculturalista centrada na ideia de diversidade apartada das desigualdades estruturais 
que as estruturam, um discurso que ao ser absorvido deforma acrítica tem levado as "armadilhas da identidade" (HAIDER, 2019).

Essas considerações conduziram a elaboração deste artigo, o qual é tributário dos resultados de duas pesquisas empíricas realizada no estado do Pará, cujo objeto foi o trabalho da/o assistente social que atuam na política de assistência social. O presente artigo tem como objetivo refletir sobre as condições de trabalho das/os assistentes sociais no estado do Pará, no contexto da acumulação capitalista estruturada pela particularidade e pela singularidade da exploração do trabalho no Brasil e na Amazônia. O texto está estruturado em cinco partes, incluindo a parte introdutória e as considerações gerais: Primeiramente se discorreu sobre as transformações societárias e a reconfiguração do papel da Amazônia na nova divisão internacional do trabalho. Em segundo lugar, foi analisado o trabalho da/o assistente social na sociabilidade capitalista contemporânea sob a égide neoliberal de destruição de direitos, em particular, na política de assistência social. Por fım, foram problematizadas as particularidades e singularidades deste trabalho em realidade amazônica, apreendendo as repercussões nas condições e relações de trabalho.

\section{Com tanta riqueza por aí, onde é que está, cadê sua fração ${ }^{5}$ : A Amazônia e a exploração do trabalho capitalista}

Sabe-se que durante alguns séculos esta região foi considerada um imenso e perigoso espaço vazio, sendo tratada, inclusive, fora do que se considerava nação. A “concepção de vazio traz em si a ideia de que os povos originários presentes no território não representavam nada de significativo - para muitos nem gente seriam, pois não eram civilizados" (MARQUES, 2019, p.87). Dessa forma, a ocupação e a transformação das terras em instrumento gerador de lucros deveria ser uma tarefa dos de fora da região, embora tal situação não fosse explicita. $O$ extrativismo era a sua base econômica e por essa razão era considerado a causa do "atraso" da região (MARQUES, 2019 Grifos do autor). 
Essas noções atribuídas à região serviram de justificativas para a instituição de medidas políticas impostas para a região, desde o governo do presidente Cetúlio Vargas que embalado pelo clima nacionalista e da Segunda Guerra Mundial, fez promessas de trazer a civilização e ao mesmo tempo povoá-la milhões de quilômetros quadrados - até os governos da ditadura militar de 1964 (MARQUES, 2019). Assim, compreender a Amazônia enquanto fronteira estratégica para o capitalismo brasileiro torna-se imprescindível remeter à intervenção do Estado brasileiro que nos últimos cinquenta anos teve uma "autêntica intervenção geopolítica que acabou por constituir o atual mosaico de ocupação econômica e de disputas sociais e territoriais" (TRINDADE e OLIVEIRA, 2014).

Embora a trajetória da Amazônia seja reconhecida como permanente espaço propício para a acumulação primitiva de capital, até o início da década de 1940, as ações dos governos locais voltadas para o crescimento econômico da região eram poucos expressivos, assim como, as políticas de integração e/ou planejamento regional do governo federal eram débeis (TRINDADE E OLIVEIRA, 2014). Entretanto, já existiam demandas do mercado internacional por produtos da Amazônia, o que expressava uma forma clássica do uso das fronteiras para o fornecimento de matérias-primas que poderiam suprir mercados nacionais e internacionais integrados a economia capitalista.

No período Pós-Segunda Guerra Mundial, a elite regional se articulou para garantir a mínima presença do governo central na região, além de apresentarem propostas de projetos que primassem pela valorização da Amazônia. Sendo assim, na "Constituição Federal de 1946, foi inserido um artigo que tratava de um Plano de Valorização da Amazônia" (IDEM, p. 43 Grifo dos autores), o qual preconizava que a União se comprometia a aplicar uma quantia não inferior a 3\% da sua renda tributária, pelo menos por 20 anos. Inicia-se, assim, a discussão sobre o desenvolvimento, na trilha da ideologia desenvolvimentista que vinha se desenvolvendo desde os anos 1930, culmi- 
nando com a criação da Superintendência de Valorização da Amazônia - SPVEA, que se constituía em uma tentativa dos governos de capitalismo periférico em impulsionar políticas de desenvolvimento e industrialização via substituição de importação, assim como, um esforço nacional para a ocupação da região.

A fragilidade das elites econômicas conduzia a diminuição cada vez menor da intervenção estatal, inclusive, o Plano de Metas, do presidente Juscelino Kubitschek não incluiu a região Amazônia, a não ser com a construção da estrada Belém-Brasília. A ideologia nacional - desenvolvimentista se apresentava como uma estratégia de desenvolvimento que se consolidou, na América Latina, em particular, no Brasil, na década de 50, que teve como um de seus principais fundamentos a crença na intervenção estatal e no planejamento enquanto uma estratégia para tirar o Brasil da condição de país subdesenvolvido, o que exigiria políticas voltadas para o desenvolvimento regional. Consolida-se, então, uma nova divisão internacional do trabalho (DIT),

na qual alguns países do terceiro mundo que estavam em vias de industrialização passavam a receber multinacionais. Estas buscavam explorar uma força de trabalho barata e com baixo grau de organização. Aproveitavam-se, ainda da proximidade com as fontes de matérias-primas e dos favores distribuídos pelos governos locais (MARQUES, 2019, p. 107).

Com efeito, os mercados dos países dessas multinacionais estariam garantidos, assim como, se apropriavam da significativa massa de mais-valia, em grande parte enviada para os mencionados países, por meio da remessa de lucros às suas matrizes.

No Brasil, esse novo papel na DIT seria cumprido inicial e principalmente pelo Sudeste. A Amazônia consolidaria uma função destacada e com especificidade, no decorrer dos anos 1970, com os grandes empreendimentos minerais (MARQUES, 2019, p. 107). 
Afırma ainda o autor acima que a ditadura empresarial brasileira impulsionou os empreendimentos para a exploração mineral, em escala industrial, na Amazônia, os quais foram e, ainda, são voltados para o exterior. A exemplo registra-se que após o golpe militar, em 1964, o presidente Castelo Branco convidou o megaempresário estadunidense Daniel Ludwig para investir no Brasil (produção de arroz, celulose, pecuária e mineração), o qual passou a adquirir grandes extensões de terra (3,7 milhões de hectares) com controle absoluto sobre a mesma que se situava entre as fronteiras dos estados do Pará e Amapá. Nos anos 1970 e 1980, seguem as instalações de novos empreendimentos na Amazônia. No estado do Pará, podem ser destacados, o Projeto Albras/Alunorte (Barcarena-Pará), o Projeto Mineração Rio do Norte (Oriximiná-Pará), o Projeto Grande Carajás (Parauapebas-Pará) 6 .

Ao lado da instalação desses empreendimentos, "a modernização conservadora da agricultura brasileira atingiu tardia e desigualmente a Amazônia" (MARQUES, 2019, p. 200), pois nos anos 1970 a 1980 passou a ocorrer a modernização da agricultura nacional, mas, na Amazônia vivenciou-se uma espécie de antirreforma agrária com alguns traços mais forte do que no restante do país (MARQUES, 2019). Embora se constate a incorporação de tecnologias na produção de grãos e de gado nos estados da Amazônia, a saber: Mato Grosso, Tocantins, parte de Rondônia e sudeste do Pará, nesta região convive-se de forma expressiva com forças produtivas modernas e arcaicas que se relacionam com relações de produção mais desenvolvidas ou "atrasadas", a saber: aviamento, trabalho análogo à escravidão, trabalho precário:

Em conjunto ocorrem conflitos agrários e degradação ambiental [...] Ocorre, então uma agricultura/agropecuária inserida nos circuitos do agronegócio e, por consequência, também no capital financeiro, versus uma agropecuária/agricultura tecnicamente atrasada (incluindo aqui a agricultura familiar e parcelas de grande propriedade, pouco produtiva) (MARQUES, 2019, p. 201). 
Com efeito, a política de modernização que se segue com o apoio da política regional e da agenda neoliberal aprofundam a concentração de renda e a desigualdade social sob todos os aspectos, visto que,

nesta nova etapa de desenvolvimento da Amazônia, sob a égide neoliberal e de integração crescente de capitais e de financiamento autônomos, as relações de mercado nortearam crescentemente as decisões de investir no setor (MESQUITA, 2012, p.67).

Assim, com a adoção da política neoliberal adotada a partir dos anos de 1990, no Brasil, o espaço econômico dominado por grandes empreendimentos capitalistas articulados ao mercado internacional, ampliou-se consideravelmente, resultando no avanço, sem medidas, da soja, da pecuária bovina e de outras monoculturas no território amazônico (MESQUITA, 2012). Com efeito, as comunidades e os povos tradicionais são as maiores vítimas da expropriação das grandes empresas, inclusive, as estatais e, portanto, excluídos do processo da era das commodities.

Segundo Mesquita (2012), a Amazônia brasileira tem passado, nas últimas décadas, por profundas e signifıcativas mudanças:

o vazio demográfico deu lugar a outro cenário, onde se encontram duas metrópoles, mais de dezenas de médias e pequenas cidades em todos os estados (o perfil produtivo, também, não se restringe ao mero extrativismo, embora ainda seja muito forte e predatório),uma série de setores e atividades capitalistas com certa complexidade que alteram substancialmente a relação capital $\times$ trabalho $(p .74)$.

Nesse cenário é pertinente se interrogar como se apresenta o trabalho na Amazônia, em particular no estado do Pará? Ora se se constata o avanço do capital internacional na região pela exportação de commodities e sabe-se que o trabalho, é a única fonte de mais-valor, considera-se fundamental se perguntar segundo a concepção marxiana sobre as formas de trabalho existentes na região. A tentativa de 
compreensão dessa questão conduz a afırmar, a princípio, que a depredação da natureza e a superexploração da força de trabalho ${ }^{7}$ tem recriado formas de trabalho análogo ao escravo; a expulsão e a morte de posseiros, índios, trabalhadores rurais em geral; a grilagem de terras; as queimadas; a poluição de rios, lagos; e muitos outros.

Além disso, o fato de que o modelo de desenvolvimento nacional e regional tem priorizado os grandes empreendimentos econômicos que foram assentados em altas tecnologias distanciadas da realidade amazônica,

“o trabalho assalariado nunca teve expressão significativa, pois, é somente, com implantação dos grandes projetos na Amazônia gerados no contexto da Ditadura Militar que se teve formas de assalariamento" (COMES, 2012, p. 165).

Ademais, apesar de a "agricultura familiar ser, numericamente, a parcela importante em termos de ocupação da força de trabalho e do papel que representa, a segurança alimentar foi excluída do ciclo de expansão e da apropriação do excedente gerado no contento globalizado" (MESQUITA, 2012, p.75).

No que concerne à política de trabalho e emprego, para os governos da região parece que vale mais a geração de um emprego num dos novos empreendimentos (mineração, extração de madeiras, etc.), pois, apesar dos danos ambientais graves que provocam, geram impostos e, assim, são preferíveis às atividades não-geradoras de impostos como as atividades tradicionais de caboclas/os da região:

Trata-se de uma estranha contabilidade pública na qual os governos, ao prestarem contas à sociedade dos investimentos feitos visando o desenvolvimento regional, apontam apenas os ganhos, sem registrar e descontar as perdas econômicas e sociais: uma contabilidade que não leva em conta a formação de grandes massas de desempregados, constituída pelos habitantes naturais que ficam sem condi- 
ções de permanecer em suas terras, vilas e povoados depois de expulsos delas para que sejam implantados os grandes empreendimentos - que, supostamente, promoverão o desenvolvimento da região. (...) Trata-se de uma estranha lógica que não contabiliza os custos dos subsídios, vantagens e facilidades financeiras concedidas pelo setor público, que sacrifica o restante da sociedade ao canalizar esses recursos para fins privados; que não computa o desperdício dos recursos naturais implicados no processo de atração de novos capitais para a região, nem os custos de uma infraestrutura que, com frequência, serve diretamente e apenas aos empreendimentos de grandes grupos econômicos e não à população em geral (LOUREIRO, 2002, p. 115- 116).

As análises da autora acima citada parecem não deixar dúvidas sobre o permanente processo de espoliação que as populações originárias da Amazônia vivem no contexto da exploração capitalista. Esse quadro remete a inadiável luta coletiva por políticas públicas e a institucionalização de outro modelo de desenvolvimento que propicie a redistribuição da riqueza produzida na Amazônia, o que implica na construção de um projeto emancipatório.

Assim, compreender a realidade da Amazônia é, sobretudo apreender as particularidades de seu processo de internacionalização e as transformações ocorridas a partir da expansão capitalista. Tais peculiaridades incidem sobre o trabalho no cenário amazônico e, em especial, no trabalho da/o assistente social que vai sendo atravessado pela violência e crueldade histórica de ocupação e saque da Amazônia, principalmente, com relação às populações tradicionais e as riquezas naturais.

Essa dinâmica do trabalho profissional na região amazônica precisa estar articulada à compreensão do trabalho da/o assistente social na sociedade capitalista e as novas configurações presentes na contemporaneidade. É nesse sentido, que se torna fundamental entender o exercício profissional inserido nas complexidades da condição de trabalhadora/dor assalariada/o, e, portanto, de trabalho precarizado. 


\section{Nessa terra de gigantes que trocam vidas por diamantes ${ }^{8}: 0$ trabalho da/o assistente social no contexto do capitalismo ultraneoliberal}

Analisar o trabalho das/os assistentes sociais no contexto de inflexão e agudização da crise capitalista ultraneoliberal, em tempos atuais, inclusive de pandemia, implica necessariamente compreendê-lo inserida/o em um cotidiano profissional, no qual a lógica de tensionamento e esgarçamento torna-se cada vez mais presentes, na medida em que, o campo de mediação, ou seja, as políticas sociais também se alteram substantivamente, rompendo qualquer perspectiva de universalização e garantia dos direitos sociais.

Sob a ordem ultraneoliberal se explicita um novo modo de acumulação capitalista, sustentada na despossessão e espoliação radicalizada dos direitos, das estruturas sociais normativas e na constituição de novos modelos de atuação política de cariz nacionalista, protofascista e xenófoba (HARVEY, 2013). Aceleram-se no campo das políticas sociais a privatização da seguridade social, com tendência à focalização e seletividade marcadas pelo caráter pontual, compensatório, fragmentário, seletivo, focalista e racista que incidem nas condições e relações de trabalho de assistentes sociais, sobretudo na perspectiva de apreender os limites, estratégias e desafios para a materialização dos princípios norteadores presentes no projeto profissional hegemônico.

A crise capitalista e suas múltiplas dimensões, a aceleração e endurecimento da implantação das contrarreformas neoliberais, por meio da completa destruição e derruição dos direitos do trabalho e das políticas sociais ensejam novas e brutais formas de exploração e precarização das condições de trabalho que repercutem deleteriamente, no trabalho das/os assistentes sociais (BOSCHETTI, 2017).

A sistemática desregulamentação do mundo do trabalho e a expropriação de equipamentos, instrumentos e dispositivos públicos de proteção social, que são fundamentais para a garantia de reprodução da classe trabalhadora e de seus familiares, acabam por penalizar as/ os profissionais que se encontram na execução direta das políticas so- 
ciais, na medida em que, os espaços ocupacionais no qual as/os assistentes sociais executam suas atividades refletem a complexidade e a totalidade histórica vivenciada pelas/os profissionais.

Ora, essa totalidade histórica que reflete as metamorfoses no mundo do trabalho e se expressam, entre outros, pela introdução de novas tecnologias associadas às novas configurações de organização e gestão do trabalho manifestam-se nas particularidades históricas da profissão, modificando, na maioria das vezes, a direção e a funcionalidade das políticas sociais e, consequentemente, os espaços de trabalho da/o assistente social que potencializam as complexas e antagônicas relações entre as classes sociais na sociedade burguesa.

É nessa intrincada rede de relações permeada por interesses sociais antagônicos e conflitantes que a vida se realiza e se afırmam ou se negam direitos à população e da qual o/a assistente social não pode se furtar e nem se eximir, pois é no tensionamento da produção das desigualdades sociais, na reprodução material e espiritual da vida social que os/as profissionais exercem seus trabalhos (IAMAMOTO, 2009).

Os desafios colocados ao Serviço Social frente ao avanço do conservadorismo, da barbarização da vida, da destruição completa dos direitos conquistados historicamente pela classe trabalhadora, do aumento do desemprego, da informalidade e de contratos temporários, da precarização do trabalho, das novas e atípicas formas de contratação de assistentes sociais, entre elas, a modalidade de pregão, feita inclusive por meio de processos licitatórios promovidos pelo Estado atenta contra, não somente às garantias existentes ainda na legislação trabalhista, como também, em todo arcabouço jurídico-normativo construído por essa profissão (SANTOS E STAMPA, 2019).

A re-atualização do neoconservadorismo tem demandado nos espaços sócio-ocupacionais das/os assistentes sociais, atividades voltadas para o controle e censura, expressas em modelos de avaliação de situações que envolvem sujeitos moralmente criminalizados, considerados "fracassados" e "irrecuperáveis" pelas estruturas 
presentes nos equipamentos em que atuam. Têm sido chamados/ as para realizar encaminhamentos absolutamente seletistas e excludentes, em que se consideram avaliações de cunho moral, de origem de classe e condição social para negar ou possibilitar o acesso, de forma bastante limitada, ao "direito".

Nesse cenário recrudescedor um dos maiores desafios é a construção de respostas competentes e propositivos/as, que não reproduzam o "senso comum" tão habitual na profissão. Faz-se necessário enfrentar, de forma qualificada as "novas" requisições, digam-se de passagem, profundamente coercitivas, do estado policialesco. Como chama atenção Boschetti (2017),

Nesse contexto barbaramente regressivo, emergem traços renovados de conservadorismo que atingem a formação e o trabalho profissional, como o metodologismo, o teoricismo acrítico, o aligeiramento da formação e da pesquisa, o pragmatismo, o voluntarismo e o voluntariado, o contentamento com o possibilismo, que reeditam características do passado recente (p. 68).

As tensões presentes no trabalho profissional fruto das determinações sócio-históricas e suas implicações na vida social vão impactar sobremaneira nas condições e relações de trabalho da/o assistente social, ao considerar que, cada vez mais, as instituições operadas pelo Estado por meio das políticas sociais encontram-se muito mais voltadas à logica mercantilizada e seus protocolos focados em metas, eficiência, eficácia e produtividade em detrimento da lógica do direito e acesso universalizante às políticas sociais.

Nessa perspectiva vemos a intensificação das precárias condições de trabalho, condições que refletem na falta de qualidade dos serviços prestados à população. Essa falta se materializa, comumente, na ausência de equipamentos dos mais variados de suporte ao trabalho, como acesso à sistema de informatização de fluxo interno, computadores; veículos; locais ou salas impróprias para um atendimento que tenha a garantia do sigilo profissional. Vivenciam-se ainda, nestes es- 
paços situações de violação de direitos da população no atendimento de suas demandas numa espécie de reprodução das desigualdades a que esses/as usuários/as são submetidos na sociedade.

Os limites vão se revelando na dinâmica do espaço sócio-ocupacional e repercutem eticamente, tendo em vista que o esgarçamento e intensificação da precarização das condições de trabalho tem violado em última instância o que está posto no código de ética profissional, como também, no que consta na Resolução CFESS n 493/06 sobre as condições éticas e técnicas do trabalho profissional.

A apreensão desse cenário institucional e a construção ou não de estratégias profissionais articuladas com outras profissões, movimentos, partidos e população, podem contribuir para fortalecer ou limitar processos de mobilização, superação, organização e formação que incidam na construção coletiva de espaços de luta social (VASCONCELOS, 2015).

Ainda que se tenha garantida a autonomia relativa da/o assistente social, esta não se encontra pacificada, isenta das complexidades, contradições e tensões que move a teia do sistema metabólico do capital, ao contrário, se inscreve neste emaranhado de limites, desafios e possibilidades cotidianas do vir a ser profissional. Isto por que no desenvolvimento do trabalho profissional da/o assistente social, as instituições empregadoras estabelecem um leque de requisições e exigências que atravessam o fazer profissional e acabam por limitar novas estratégias e perspectivas de materialização das respostas previamente intencionalizadas e planejadas, determinando, em grande medida, a conjuntura e as circunstâncias sócio-políticas em que se realiza, se concretiza e se objetifica o projeto ético-político da profissão no interior dos espaços laborais. Essa autonomia relativa permite, portanto, aos/as assistentes sociais romperem com perspectivas, segundo Raichelis (2018)

deterministas e/ou voluntaristas para se apropriar da dinâmica contraditória dos espaços institucionais e poderem formular estratégias individuais e coletivas que escapem da reprodução acrítica das requisições do poder institucional (p.36). 
Importante aqui lembrar que como profissão que se inscreve na divisão sóciotécnica das relações sociais de produção capitalista, o Serviço Social também se vê influenciado por uma perspectiva mais técnico-instrumental e racionalista presente no formato da política social, o que acaba por impedir muitas vezes que se apreenda a realidade em sua totalidade, diluindo as estratégias profıssionais em intervenções voluntaristas, pragmatistas, alienadoras, imediatistas, fragmentadas, pulverizadas e descontextualizadas dos tensionamentos existentes nas relações antagônicas das classes sociais.

\section{Esse rio é minha rua ${ }^{9}$ : Condições de trabalho da/o assistente social em contexto amazônico}

A ausência de respeito acerca das particularidades e singularidades regionais expressas por ações governamentais que homogeneízam os sujeitos transformando-os em pauperizados, como é o caso de índios e quilombolas (TEIXEIRA, 2008) parece não deixar dúvida sobre o racismo institucional que tem predominado na região. Segundo Almeida (2019), como uma modalidade do racismo estrutural, o racismo institucional, consiste na forma como as instituições reproduzem as condições para o estabelecimento e a manutenção da ordem social. Ou seja, trabalhar com a ideia de racismo estrutural e suas derivações, é entender que "a estrutura social é constituída por inúmeros conflitos de classe, raciais, sexuais etc., o que significa que as instituições também podem atuar de maneira conflituosa, posicionando-se dentro do conflito" (ALMEIDA, 2019, p. 48) mesmo que o conflito seja escamoteado pelo poder dominante, e por isso a recorrência à homogeneização. Evidencia-se, portanto, o imbricamento capitalismo e racismo, como estruturas de exploração e opressão.

Trabalhadoras/es e usuárias/os das políticas sociais experimentam cotidianamente o tratamento desigual que é dirigido à Amazônia, como espaço físico diferenciado e ocupado por pessoas de "menos valor", para qual qualquer coisa serve. A explicação do descaso com 
as particularidades e singularidades regionais pela perspectiva das desigualdades estruturais que remetem à classe e à raça também encontra respaldo quando se observa que mesmo com a gestão federal do Partido dos Trabalhadores (2003 a 2014), que reconheceu a dívida que o Estado brasileiro tem com as pessoas que vivem na Amazônia e a relevância das singularidades socioculturais, o reconhecimento se restringiu ao discurso governamental formalizado.

A referida gestão caracterizada pelo estabelecimento de uma interlocução com movimentos sociais e ativistas dos direitos humanos, resultou na criação de normativas e práticas inovadoras de políticas sociais estimulando gestões que obedeciam às diretrizes de participação de democratização dos processos e tendiam a aumentar e qualificar o trabalho das/os servidoras/es públicas/os, como foi o caso da criação do Sistema Único de Assistência Social (SUAS) em 2005.

O SUAS, ao admitir a existência do fator amazônico, ou seja, a indiferença com a particularidade e a singularidade das desigualdades no contexto amazônico, aprovou a Res. $n^{\circ} 33 / 2012$, art. 62, que reconhece: "[...] o co-fınanciamento dos serviços socioassistenciais de proteção social básica e especial deverá considerar fatores que elevam o custo dos serviços na Região Amazônica [...]" (BRASIL, 2012, p. 21), mas as limitações impostas pelas organizações multilaterais, principalmente o Fundo Monetário Internacional (FMI) de restrições em gastos em políticas sociais inviabiliza a resolução.

Dados das pesquisas de campo mencionadas na introdução deste artigo, indicam que a implantação do SUAS no Pará e o cumprimento da referida resolução registram relatos recorrentes de que o grande nó da Política de Assistência Social continuava sendo o tratamento superficial dos reais interesses da Região. Relatos sobre orçamento restritivo e compra de equipamentos que não correspondiam com as solicitações encaminhadas eram constantes. No bojo das críticas se sobressai as condições de trabalho das/os assistentes sociais no estado do Pará, em que é possível observar uma exacerbação da precarização dessa/e profissional. 
A Norma Operacional Básica de Recursos Humanos (NOB-RH) de 2006, considerada uma das principais inovações apresentadas pelo SUAS, por colocar em evidência a constituição de uma equipe de referência da Política, segundo as/os trabalhadoras/es ao adotar a premissa da "equipe mínima", legitima a maioria dos gestores municipais a contratarem até uma/um assistente social, em muitos municípios do Estado, sendo a/o mesma/o responsável pela operacionalização das ações do Centro de Assistência Social (CRAS).

Na realidade amazônica é possível perceber que as/os assistentes sociais que trabalham no SUAS com populações ribeirinhas, quilombolas e indígenas tem na dimensão da mobilidade um elemento muitas vezes determinante para a execução de suas atividades, pois o cenário amazônico contrasta com o que se encontra no eixo sudeste-sul e no nordeste, por exemplo. O cotidiano profissional deste lado de cá inclui grandes distâncias, no qual, muitas vezes, os rios aparecem como única possibilidade de acesso, ao lado das variações climáticas relevantes que conjugadas com a complexidade de deslocamento pelos rios acabam por influenciar consideravelmente o tempo e a qualidade de trabalho disponível. Assim, o deslocamento de transporte rodoviário e fluvial em ônibus extremamente danificados devido às condições das estradas, bem como, a utilização de barcos volantes, inapropriados para o uso de determinados rios se constitui outra ilustração da exacerbação da precarização do trabalho das/os assistentes sociais.

O deslocamento entre áreas de terra firme e fluvial, muitas vezes no mesmo dia, se justifica pelo fato de que é reduzido o número de CRAS físicos e a existência dos CRAS itinerantes, fazendo com que a/o profissional se desloque a uma escola ou centro comunitário para desenvolver determinadas ações, mas principalmente pela subcontratação através de vínculos temporários em duas ou três secretarias devido os baixos salários e a ausência de concursos públicos. Outro dado importante que explícita a realidade amazônica se comparada com o eixo sudeste-sul. 
As transformações no mundo do trabalho e, consequentemente, na alteração do perfil e direção das políticas sociais afetam o trabalho das/os assistentes sociais. Isso significa dizer que a intensifıcação da precarização das condições de trabalho se materializa entre outros, pela falta de infraestrutura, baixos salários; altas taxas de adoecimento/afastamento, etc. A licença saúde é um recurso bastante utilizado pelas/os concursadas/os que pretendiam trabalhar em condições favoráveis. Dados coletados indicam que faixa salarial da maioria das/ dos assistentes sociais que trabalham nos municípios mais afastados da capital recebem entre 2 (dois) a 3 (três) salários mínimos e 20\% recebem até (dois) salários mínimos.

De acordo com os relatos dos sujeitos das pesquisas citadas, em determinados municípios o tempo de contratação de uma/um assistente social gira em torno de 06 (seis) meses a um ano. O pagamento da equipe contratada até 2018 foi realizado com recursos transferidos pela esfera federal de governo, ou seja, resultado dos projetos aprovados. A questão dos baixos salários, todavia, é uma realidade mesmo entre as/os profissionais concursadas/os, que também fazem uso da estratégia de subcontratação embora possam contar com um "fıxo". Nas observações de campo se encontrou assistentes sociais, recém-formadas no Ensino à Distância, desempenhando a profissão de forma voluntária, na esperança de ser contratada posteriormente.

A infraestrutura do local de trabalho é outra expressão da exacerbação da precarização do trabalho da categoria, $61 \%$ indicam que trabalham em ambientes com algum tipo de ruído, fator esse que pode comprometer a qualidade do trabalho realizado. Essas condições de trabalho, também reverberam na saúde dessas/es quando informam que $28 \%$ tem sentimentos de tristeza e angústia e $25 \%$ dormem mal ou têm insônia, indicando que o esvaziamento do sentido do trabalho, os limites para efetivar o compromisso profissional em direção à garantia de direitos, os critérios de endurecimento e seletividade junto às/ os usuárias/os; as péssimas condições técnicas e éticas do trabalho 
profissional; a lógica gerencialista de funcionamento das instituições governamentais que estimulam o individualismo, a tensão e a competitividade produzem um esgotamento físico e psíquico nas/nos assistentes sociais (RAICHELIS, 2011).

Constata-se, portanto, que o trabalho dessas/es profissionais no contexto amazônico tem um grau maior de dificuldades pelos poucos recursos e infraestrutura para se realizar, como também, pelas imensas dificuldades de acesso e mobilidade a que estão submetidas/os e que a efetivação deste trabalho sob estas condições parecem terem sido transformadas em uma espécie de competência profissional, revelando o lado perverso e contraditório desta sociabilidade, que na maioria das vezes responsabiliza e exige um atendimento de qualidade pela/o profissional mesmo tendo menos recursos públicos e menos tempo de trabalho.

Nesse sentido, as condições de trabalho das/os assistentes sociais em contexto amazônico nos municípios pesquisados apesar de uma norma específica sobre valorização de trabalhadoras/es, como a RH/SUAS-2006, aproxima, pela precarização do trabalho e dos serviços, a/o profissional e a/o usuária/o, que na perspectiva da desigualdade estrutural de classe e raça, constituem face da mesma moeda do racismo estrutural e institucional.

\section{Considerações Gerais}

Palco de possibilidades emancipatórias e manipulatórias, o cotidiano, como espaço privilegiado do trabalho profissional da/o assistente social conduz tanto à práticas repetitivas, mimetizadas, superficiais e espontaneístas, como também, possibilita, por um conjunto de sucessivas mediações, momentos e instantes de suspensão e elevação do singular para o humano-genérico, permitindo uma existência prenhe de sentido, mesmo que provisoriamente, numa espécie de encontro consigo, com os outros homens e mulheres e com o mundo à volta. Esses instantes de sublimação dos sujeitos promovem uma volta à co- 
tidianidade não mais igual ao que se encontravam, mas modificados em seu nível de consciência e apreensão do real (GUERRA, 1995).

Esse quadro, no estado do Pará, se torna mais grave em decorrência do aprofundamento da crise econômica provocada pela pandemia do novo coronavírus que vem afetando diversos setores. Somente no mês de abril, o número de desemprego foi recorde, segundo o Departamento Intersindical de Estatística e Estudos Socioeconômicos (DIEESE, 2020). Foram 20.293 (vinte mil, duzentos e noventa e três) desligamentos. O número de demissões é maior que o de admissões, que chegou a 11.931(onze mil e novecentos e trinta e um), gerando saldo negativo de 9.362 postos de trabalho no setor formal da economia.

Em números absolutos, o Pará atingiu 413 (quatrocentos e treze) mil desempregadas/os ao fim de março deste ano (IBCE, 2020). O dado representa uma alta acentuada de 57 (cinquenta e sete) mil pessoas na margem de desocupação em relação ao trimestre anterior, de 356 mil (trezentos e cinquenta e seis), ou seja, mais de 16\%. Já na comparação com o $1^{\circ}$ trimestre de 2019, a pesquisa aponta um decréscimo de 29 mil desempregados/as, ou seja, uma baixa de 6,5\% em relação as 441 mil pessoas nesta situação.

O estudo, realizado por meio da Pesquisa Nacional por Amostra de Domicílios Contínua (PNAD Contínua), divulgado em fevereiro de 2020, evidencia que os índices de trabalho informal no Pará vêm crescendo. Entre 2016 e 2019 os índices foram respectivamente de 60,8\% e $62,4 \%$. Essa pesquisa mostra que, no primeiro trimestre de 2019 , havia mais de 1,48 milhões de trabalhadoras/es informais no interior do Pará, correspondente a 62,5\%.

Assim, é possivel deduzir que essas formas de trabalho, as quais as/os trabalhadoras/es no estado do Pará estão inseridas/os se apresentam precárias, visto que, não dispõem de proteção social, sobretudo, com a destituição de direitos trabalhistas e previdenciários, com a aprovação das “contrarreformas”, com a Lei da terceirização n 13.429 
de março de 2017) e a PEC95/2016 que congela os gastos sociais por 20 anos. Esse quadro remete a inadiável luta coletiva por políticas públicas e institucionalização de outro modelo de desenvolvimento que propicie a redistribuição da riqueza produzida na Amazônia, o que implica na construção de um projeto anticapitalista.

Vê-se, portanto, que o trabalho das/os assistentes sociais encontra-se determinado na trama da complexidade da realidade contemporânea e que tem exigido da categoria profissional, uma análise crítica e rigorosa do movimento do real na perspectiva de desmistificá-lo e apreendê-lo em suas determinações sócio-históricas, particulares e singulares, como é o caso da Amazônia, compreendendo os limites e possibilidades do trabalho profissional e da efetivação do projeto profissional hegemônico.

\section{Referências}

ALMEIDA, Silvio Luiz de. Racismo Estrutural. São Paulo. Sueli Carneiro. Pólen, 2019 .

BOSCHETTI, I. Agudização da barbárie e desafios ao Serviço Social. Serviço Social \& Sociedade, São Paulo, n. 128, p. 54-71, jan./abr. 2017. Disponível em: https://www.scielo.br/pdf/sssoc/n128/0101-6628-sssoc-128-0054.pdf. Acesso em: 20 jun. 2020.

BRASIL. Ministério do Desenvolvimento Social e Combate à Fome. Secretaria Nacional de Assistência Social. NOB/SUAS. Res. CNAS, nº 33 de 2012.

BRASIL. LEI N 13.429, DE 31 DE MARÇO DE 2017. Presidência da República Secretaria-Geral/Subchefia para Assuntos Jurídicos. Disponível em http:// www.planalto.gov.br/ccivil_03/_ato2015-2018/2017/lei/13429.htm. Acesso em 20/05/2020.

BRASIL. PRESIDÊNCIA DA REPÚBLICA SECRETARIA-GERAL/Subchefia para Assuntos Jurídicos. EMENDA CONSTITUCIONAL N 95, DE 15 DE DEZEMBRO DE 2016. Disponível em http://www.planalto.gov.br/ccivil_03/constituicao/ emendas/emc/emc95.htm. Acesso em 30 de maio de 2015.

CARCANHOLO, Marcelo D. Dependência, Super-explotación del trabajo y crises: Uma interpretación desde Marx. Marid: Maia Ediciones, 2017. 
CONSELHO FEDERAL DE SERVIÇO SOCIAL (CFESS). Resolução n. 493/2006. Estabelece as condições éticas e técnicas para o exercício do trabalho. Disponível em: http://www.cfess.org.br/arquivos/Resolucao_493-06.pdf>. Acesso em: 20 jun. 2020.

DEPARTAMENTO INTERSINDICAL DE ESTATÍSTICA E ESTUDOS SOCIOECONÔMICOS (DIEESE). Cerca de 20 mil desligamentos são reflexos da crise econômica provocada pela pandemia do novo coronavírus. Disponível em https://g1.globo.com/pa/para/noticia/2020/05/29/para-tem-novo-recorde-de-desemprego-em-abril-diz-dieese.ghtml.Belém. 29/05/2020. Acesso em 10 jun. 2020.

GUERRA, Yolanda. A instrumentalidade do Serviço Social. São Paulo: Cortez, 1995.

HAIDER, Asad. Armadilha da Identidade: raça e classe nos dias de hoje. São Paulo, Veneta. 2019.

HARVEY, David. Os Limites do Capital. São Paulo: Boitempo, 2013.

IAMAMOTO, M. Os espaços sócio-ocupacionais do assistente social. In: Serviço Social: direitos e competências profissionais. In: Programa de Capacitação continuada para assistentes sociais. Brasília: CFESS/ABEPSS/CEAD, 2009.

INSTITUTO DE PESQUISA ECONÔMICAAPLICADA (IPEA, 2017). Atlas da Vulnerabilidade Social. Disponivel em: https://www.ipea.gov.br/portal/images/ stories/PDFs/relatoriopesquisa/170823_lancamento_ivs_metodologia_e_ primeiros_resultados.pdf. Acesso em: 15 jun. 2020.

GOMES, Vera Lúcia Batista. Trabalho e Desenvolvimento na Amazônia: Notas para a reflexão o estado do Pará. In: GOMES, Vera Lúcia Batista, VIEIRA, Ana Cristina de Souza e NASCIMENTO, Maria Antônia Cardoso (org.). O Avesso dos Direitos: Amazônia e Nordeste em questão. Recife (Pe): Editora Universitária UFPE, 2012.

G1. PA-Belém. Pará registra 57 mil novos desempregados no primeiro trimestre de 2020, aponta IBCE. Disponível em https://g1.globo.com/pa/para/ noticia/2020/05/15/para-registra-57-mil-novos-desempregados-no-primeiro-trimestre-de-2020-aponta-ibge.ghtml, acesso em 20.05.2020

LOSCHI, Marília. PNAD Contínua: Desemprego cai em 16 estados em 2019, mas 20 têm informalidade recorde. Disponível em https://agenciadenoticias. ibge.gov.br/agencia-noticias/2012-agencia-de-noticias/noticias/26913-de- 
semprego-cai-em-16-estados-em-2019-mas-20-tem-informalidade-recorde. Acesso em 18/05/2020.

LOUREIRO, Violeta Refkalefsky. Amazônia: uma história de perdas e danos, um futuro a (re)construir. In: Estudos Avançados. vol.16 no.45 São Paulo May/Aug. 2002. Disponível em: https://doi.org/10.1590/S010340142002000200008, acesso em: 20 abr. 2020.

MARQUES, Gilberto de Souza. Amazônia: riqueza, degradação e saque. São Paulo: Expressão Popular, 2019.

MESQUITA, Benjamim Alvino de. A Atuação governamental, as forças de mercado e a inserção da Amazônia no ciclo das commodities. In: LOPES, Josefa Batista; COUTINHO, Maria Aparecida (orgs.). Crise do Capital, lutas sociais e políticas públicas. São Paulo: Xamã, 2012.

RAICHELIS, R. Serviço Social: trabalho e profissão na trama do capitalismo contemporâneo. In: A nova morfologia do trabalho no serviço social. São Paulo: Cortez, 2018, p. 25-65.

RAICHELIS, R. O assistente social como trabalhador assalariado: desafios frente às violações de seus direitos. Serviço Social e Sociedade, São Paulo, n. 107, p. 420-437, 2011.

SANTOS, Tatiane Valéria C. S; STAMPA, I. Contratação por pregão: formas atípicas de trabalho de assistentes sociais no Brasil recente. Ser Social, Brasília, v. 21, n. 44, jan./jun. 2019. Disponível em: https://periodicos.unb.br/index. php/SER_Social/article/view/23481. Acesso em: 20 jun. 2020.

TEIXEIRA, Joaquina. Meio Ambiente, Amazônia e Serviço Social. Em Pauta. n. 21, 2008.

TRINDADE, José Raimundo Barreto (org.) Seis Décadas de Interpretação Estatal na Amazônia: A SPVEA, auge e crise do ciclo ideológico do desenvolvimentismo brasileiro. Belém: Paka-Tatu, 2014.

VASCONCELOS, A.M. A/O assistente social na luta de classes: projeto profissional e mediações teórico-práticas. São Paulo: Cortez, 2015.

\section{Notas}

1 Doutora em Serviço Social (UFRJ) e professora do Curso de Graduação e Pós-Graduação em Serviço Social - UFPA/Brasil. https://orcid.org/0000-00026976-7985. Email: danicastilho@ufpa.br 
2 Doutora em Serviço Social (PUCSP) e professora do Curso de Graduação e Pós-Graduação em Serviço Social - UFPA/Brasil. https://orcid.org/0000-00022931-1967. Email: mariaant@ufpa.br

3 Doutora em Sociologia do Trabalho - Université de Picardie Jules Vernes (FR) e professora do Curso de Graduação e Pós- Serviço Social - UFPA/Brasil. https:// orcid.org/0000-0002-8146-5082. Email: veragomesbelem@hotmail.com

4 Projeto de Pesquisa "Estudo avaliativo da implementação do Sistema Único de Assistência Social no Brasil”, período 2014 a 2018, com financiamento do ConseIho Nacional de Desenvolvimento Científico e Tecnológico (CNPQ) e o Projeto de Pesquisa "Trabalho e Saúde da/os assistentes sociais que atuam na área da Seguridade Social nos estados Acre, Amazonas e Pará", ambos de âmbito nacional, da qual, em nível regional, participam as autoras deste artigo. No âmbito regional, a pesquisa obteve aprovação do Comitê de Ética em Pesquisa do Instituto de Ciências da Saúde da UFPA - CEP-ICS/UFPA, em 24 de outubro de 2019, CAEE: 12469819.9.0000.0018.

5 Trecho da música "Até quando esperar" do grupo musical Plebe Rude.

6 Registra-se que neste mesmo período houve a instalação de outros empreendimentos, na Amazônia, podendo ser destacado: Projeto Alcoa para a produção de alumínio no estado do Maranhão. Esse empreendimento recebeu a concessão de 11\%de toda a área física do município de São Luís e 57\%da área do distrito industrial da cidade (MARQUES, 2019).

7 Segundo Carcanholo (2017), a teoria marxista da dependência entende a superxploração da força de trabalho como formas/mecanismos do aumento da taxa de mais-valia, como conjunto de todas as situações que permitem o aumento do grau de exploração da força de trabalho a partir da redução dos salários a um nível inferior ao valor dessa.

8 Trecho da música "Terra de gigantes" do grupo musical Engenheiros do Hawaii

9 Trecho da música "Esse rio é minha rua" dos compositores paraenses Ruy GuiIherme Paranatinga Barata e Paulo André Barata 


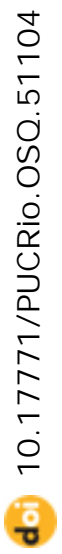

